\title{
Multiple extra-articular synovial cyst formation: case report and review of the literature
}

\author{
Shih-Yang Chen, Naoyuki Kamatani, Sadao Kashiwazaki
}

\begin{abstract}
Objective-To investigate the clinical manifestations and the treatment strategy of a very rare entity of disease manifesting as multiple extra-articular cystic synovitis with recurrent polyarthralgia.

Methods-A 47 year old male patient with multiple extra-articular synovial cysts was followed up prospectively for 13 years. The clinical manifestations and response to various treatments were recorded. Comparisons are made among the five reported cases (including the present case).

Results-Multiple synovial cysts over the tendon sheath and bursae appeared successively with and without antecedent growth of nodules during 13 years of follow up. Although polyarthralgia and high titred rheumatoid factor persisted throughout the course, there were no roentgenographical changes of joints specific to rheumatoid arthritis (RA). The synovial cysts and arthralgia failed to respond to any of the disease modifying anti-rheumatic drugs (DMARDs) prescribed. Systemic involvements such as pulmonary interstitial fibrosis and skin ulcers were also noted, but they were not progressive.

Conclusions-Multiple extra-articular cystic synovitis is an uncommon disease entity closely related to RA. It has been reported exclusively in Japanese subjects and therefore some cultural factors, either genetic or environmental, may contribute to its development.

(Ann Rheum Dis 1998;57:169-171)
\end{abstract}

Synovia exist not only in joint spaces but also in bursae and tendon sheaths. The synovia of bursae and tendon sheaths, like articular synovia, can be subject to various stimuli that cause inflammation. ${ }^{1}$ Isolated synovial cysts of bursae or tendon sheaths are not uncommon, but reports of multiple extra-articular cystic synovitis are very rare and exclusively concern Japanese people..$^{2-5}$ The present report deals with another case of multiple extra-articular cystic synovitis and a comparison is made with the four previously reported cases.

Correspondence to: $\mathrm{Dr} \mathrm{N}$ Kamatani, Institute of Rheumatology, Tokyo Women's Medical College, 10-22 Kawada-cho, Shinjuku-ku, Tokyo 162, Japan.

Accepted for publication 3 February 1998
A 47 year old male patient was afflicted with subcutaneous nodules over the dorsum of the proximal interphalangeal joint of the left middle finger and left elbow since 1981. Recurrent polyarthralgia without morning stiffness was also noted. The nodules persisted and he came to our outpatient department in 1984.

At that time, roentgenograms of hand and foot joints and a chest radiograph appeared normal. Laboratory examinations revealed the following: serum rheumatoid factor $1280 \times$ (by haemagglutination test), negative antinuclear antibodies test, $\mathrm{C}$ reactive protein $1+$, erythrocyte sedimentation rate $41 \mathrm{~mm} 1 \mathrm{st}$ h, normal $\mathrm{CH}_{50}$, normal immunoglobulin subclassifications, normal biochemical examinations (including albumin, lactate dehydrogenase, total and conjugated bilirubin, aspartate aminotransferase, alanine aminotransferase, total cholesterol, triglyceride, and uric acid), WBC count $9.1 \times 10^{9} / 1$ (segment 49 , band 3 , lymphocyte 44 , monocyte 2 , and eosinophil $2 \%$ ), and normal red cell count, haemoglobin, mean corpuscular volume, and platelet counts. There were no abnormal physical findings except for subcutaneous nodules over the dorsum of the proximal interphalangeal joint of the left middle finger and left elbow.

In 1985, the left olecranon bursa underlying the nodules began to swell insidiously without a history of frequent friction. Aspirated bursal fluid appeared chyliform without visible crystals, as observed under a birefringent microscope. WBC count of bursal fluid was $8.7 \times$ $10^{9} / 1$ (segment 81.5 , lymphocyte 16.5 , atypical lymphocyte 1.5 , and histiocyte $0.5 \%$ ). There was no growth of bacteria, tuberculi or fungi from bursal fluid cultures. Histological study of the resected bursa revealed a papillary hyperplastic synovium, a dense distorted connective tissue layer, numerous rheumatoid nodules (fig 1), eosinophilic material in the bursal wall, and hyperplastic blood vessels. The olecranon bursa enlarged progressively and reached a size of $15 \times 5 \times 3 \mathrm{~cm}$ in 1996. Aspirated fluid from this bursa at that time appeared chyliform macroscopically and revealed quantities of lipid-like material under the light microscope.

In addition to the left olecranon bursa, painless swellings developed successively over the right olecranon bursa, bilateral trochanteric bursae, bilateral prepatellar bursae, and bilateral retrocalcanean bursae since 1988 without chronological relation to arthralgia. Some of the lesions appeared as erythema at first, while some did not. The swellings were accompanied by local heat and general malaise. Though the bursal fluid was aspirated frequently to relieve the annoyance, it always reaccumulated. Sometimes the bursal fluid appeared clear but at other times it appeared chyliform.

In 1993, nodules adhering to tendons of the bilateral extensor digiti minimi, right extensor 


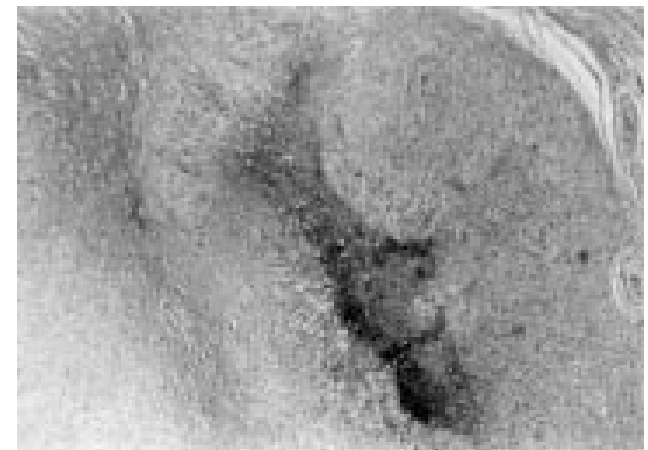

Figure 1 Histological section of the wall of the olecranon bursa, showing one of the rheumatoid nodules surrounding the hyperplastic synovium. The nodule is embedded in the centre of hyperplastic vessels. Haematoxylin and eosin stain, original magnification $\times 40$.

pollicis longus, left extensor pollicis longus and brevis, left extensor digitorum indicis of hands (fig 2(A)), left peroneus longus, and bilateral extensor hallucis longus of foot also appeared. Some of the nodules subsequently developed into cystic swellings. Another cystic swelling adhering to the tendon sheath of the extensor digitorum longus without antecedent development of nodules was also noted on the left foot since 1995 (fig 2(B)). Mild swan neck deformity and ulnar deviation developed since 1997. At the same time, roentgenography revealed compression osteopenia over the left first metacarpal bone and ulnar subluxation of the first metacarpotrapezial joint. There were no roentgenographic changes specific to rheumatoid arthritis (RA).

Morning stiffness following polyarthralgia developed in 1984, early in the course of the disease, and subsided in the 1990s after treatment with various disease modifying antirheumatic drugs (DMARDs), including gold, D-penicillamine, and sulphasalazine. However, the arthralgia and synovial cysts failed to respond to any of the DMARDs. Methotrexate was not prescribed in case it caused exacerbation of nodules and pulmonary fibrosis, and the patient refused to take prednisolone.
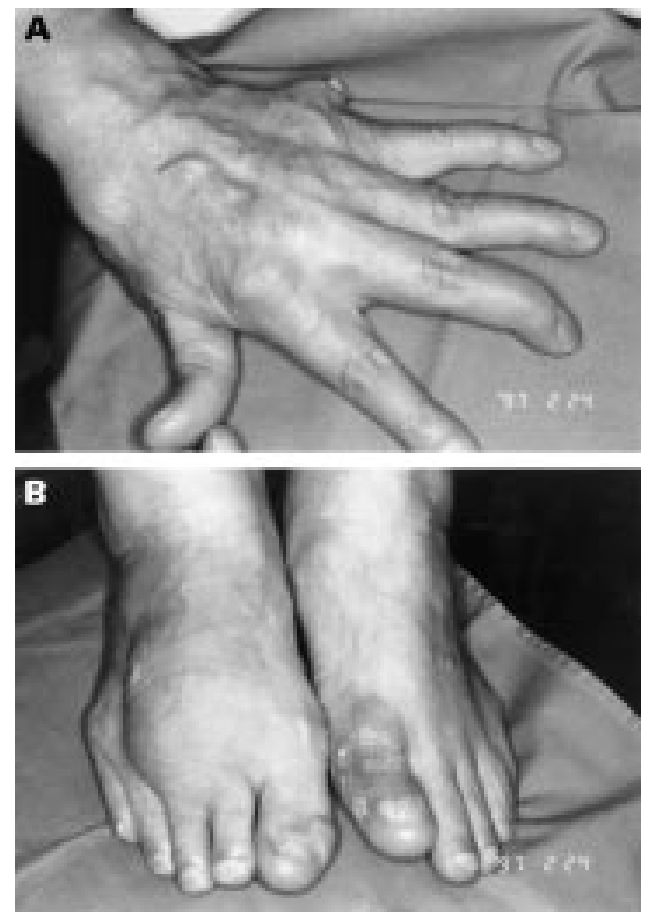

Figure 2 (A) Synovial cysts over tendon sheaths of left extensor digiti minimi, extensor pollicis longus and brevis, and extensor digitorum indicis. Swan neck deformity can also be seen. (B) Huge synovial cysts over tendon sheath of right extensor digitorum longus and left peroneus longus. Scar of skin ulcer over left big toe can be seen.

Pulmonary interstitial fibrosis and skin ulcers of the left foot (fig 2(B)) developed insidiously in 1985 and in 1992. They were not progressive and were cured with supportive treatment only. There were no other symptoms or signs of systemic involvements, except for livedo reticularis bilaterally over the lower legs since 1996.

In 1997, an autoantibodies screen revealed negative results of antinuclear antibodies, anti-Ro antibodies, anti-La antibodies, antineutrophil cytoplasmic antibodies, lupus anticoagulant tests, and anti- $\beta_{2}$ glycoprotein-1 anticardiolipin antibodies. The HLA type was

Table 1 Manifestations of reported cases of multiple extra-articular synovial cyst formation

\begin{tabular}{|c|c|c|c|c|c|}
\hline Reporter & Takahashi et al & Matsuda et al & Yasuda et al & Setoyama et al & Chen et al (present case) \\
\hline Sex & Female & Male & Female & Female & Male \\
\hline Age of onset ${ }^{\star}$ & 61 & 71 & 55 & 54 & 48 \\
\hline $\begin{array}{l}\text { Locations of } \\
\text { involvements }\end{array}$ & $\begin{array}{l}\text { Bilateral knees, elbows, } \\
\text { left foot, wrist, tendons } \\
\text { of dorsum of left hand }\end{array}$ & $\begin{array}{l}\text { Bilateral knees, elbows, } \\
\text { dorsa of feet }\end{array}$ & $\begin{array}{l}\text { Bilateral axillae, scapulae, } \\
\text { hips, sacrum }\end{array}$ & $\begin{array}{l}\text { Bilateral knees, } \\
\text { elbows, dorsa of } \\
\text { hands and feet, left } \\
\text { ankle }\end{array}$ & $\begin{array}{l}\text { Bilateral elbows, knees, hips, } \\
\text { tendons on bilateral dorsa of } \\
\text { hands, tendons of dorsum of left } \\
\text { foot }\end{array}$ \\
\hline $\begin{array}{l}\text { Presence of } \\
\text { polyarthralgia }\end{array}$ & Yes & Yes & Yes & No & Yes \\
\hline $\begin{array}{l}\text { Radiological evidence of } \\
\text { RA } †\end{array}$ & Not described & No & Not described & No & No \\
\hline Rheumatoid factor & +++ & + & $296 \mathrm{u} / \mathrm{ml} \ddagger$ & ++ & +++ \\
\hline $\mathrm{ESR}(\mathrm{mm} \mathrm{1st} \mathrm{h)}$ & 60 & 31 & 100 & 24 & 41 \\
\hline CRP & Not described & +++ & ++ & Negative & ++ \\
\hline $\begin{array}{l}\text { Pulmonary interstitial } \\
\text { fibrosis }\end{array}$ & Not described & Yes & Yes & No & Yes \\
\hline $\begin{array}{l}\text { Skin lesions on bilateral } \\
\text { lower legs }\end{array}$ & No & No & Subcutaneous bleeding & No & Skin ulcer, livedo reticularis \\
\hline Histology & $\begin{array}{l}\text { Synovial hyperplasia, } \\
\text { giant cells, rheumatoid } \\
\text { nodules in the wall }\end{array}$ & $\begin{array}{l}\text { Synovial hyperplasia, } \\
\text { lymphocyte infiltration, } \\
\text { hyaline change nodules } \\
\text { in the wall }\end{array}$ & $\begin{array}{l}\text { Synovial villous } \\
\text { hyperplasia, eosinophilic } \\
\text { material, dense } \\
\text { connective tissue, } \\
\text { hyperplastic blood vessels, } \\
\text { monocyte infiltration }\end{array}$ & $\begin{array}{l}\text { Synovial villous } \\
\text { hyperplasia, } \\
\text { eosinophilic material, } \\
\text { dense connective } \\
\text { tissue, xanthoma cells }\end{array}$ & $\begin{array}{l}\text { Synovial villous hyperplasia, } \\
\text { rheumatoid nodules, eosinophilic } \\
\text { material, dense connective tissue, } \\
\text { hyperplastic blood vessels, } \\
\text { plasma cell infiltration }\end{array}$ \\
\hline
\end{tabular}

^Age of onset of synovial cystitis. †Roentgenographical evidences of osteoporosis, joint space narrowing, bony erosions, subchondral cysts, deformity, or ankylosis. $\ddagger$ Measured by laser nephelometry (normal range $<10 \mathrm{u} / \mathrm{ml}$ ). 
A-24, A-26 at A locus, B-51, B-52 at B locus, DR-12, DR-15 at DR locus, and DQ-1, DQ-3 at DQ locus.

\section{Discussion}

Synovial cysts can originate from joints, bursae or tendon sheaths. ${ }^{6}$ It is difficult to discriminate between cysts from bursae and those from tendon sheaths, because both share a close anatomic relationship and a similar histological appearance. ${ }^{6}$ Nevertheless, if discovered early, cysts from tendon sheaths can be demonstrated by their firm adherence to tendons.

Multiple synovial cystic formations over all four limbs is very uncommon and has been reported exclusively in Japanese subjects, though swellings of bilateral olecranon or subacromial bursae have been reported in a white population. ${ }^{78}$ Some genetic or environmental factors specific to the Japanese may be involved. According to the literature (table 1), ${ }^{2-5}$ multiple extra-articular cystic synovitis represents an inflammatory cystic disease involving multiple synovial tissues except for the articular synovia. Although it was misnamed as "multiple bursitis",245 we suspect that the reported lesions on the dorsa of hands and feet originated from tendon sheaths, as in our case. Therefore, the name "multiple extraarticular cystic synovitis" seems more comprehensive and consequently more appropriate.

This disease entity tends to affect older patients without regard to sex (table 1). Apart from the case reported by Setoyama et al, ${ }^{2}$ all cases presented with polyarthralgia, deformity, a marked increase in acute phase reactant, and positive rheumatoid factor. Development of synovial cysts followed the onset of polyarthralgia within one year, except for the case reported by Yasuda et al. ${ }^{3}$ Morning stiffness was noted only in our case and that reported by Matsuda et al. ${ }^{4}$ Synovial cysts first involved the bursae around large joints, such as knee, ${ }^{45}$ elbow, or shoulder, ${ }^{3}$ and then spread to more peripheral synovial tissues. Histological examination of synovial cysts showed common characteristics of synovial villous hyperplasia, eosinophilic depositions, dense fibrous connective tissue coat, and infiltration of inflammatory cells. However, in no case is there evidence of involvement of, nor evidence of communications with, the articular synovia. In those reports describing roentgenographic findings, ${ }^{24}$ as in our case, there was no roentgenographic evidence specific to RA. To date, no effective treatment for the synovial cysts has been reported.

All cases (except for that reported by Setoyama et $\mathrm{al}^{2}$ ) fulfilled the revised American Rheumatism Association criteria for classification of RA, ${ }^{9}$ and RA was diagnosed by the previous authors. ${ }^{3-5}$ A roentgenogram of joints might be normal in early RA, ${ }^{10}$ but our case showed no roentgenographic change specific to RA throughout 15 years of polyarthralgia. It is difficult to establish if there is RA or not, but the manifestations are not typical of RA.

Three of the four cases with polyarthralgia developed pulmonary interstitial fibrosis and two were combined with skin lesions bilaterally on the lower legs. However, both manifestations were mild and non-progressive, and our patient lived well for more than a decade. Other extra-articular manifestations, such as subcutaneous rheumatoid nodules preceding the development of synovial cysts, were also identified in our patient and that reported by Takahashi et al. ${ }^{5}$ The extra-articular rheumatoid manifestations (rheumatoid nodule, pulmonary interstitial fibrosis, and skin ulcer) tend to be accompanied by a high titre of rheumatoid factors and could occur when arthritis is quiescent or mild. ${ }^{11}$ Multiple extra-articular cystic synovitis also has these features and therefore they may be closely associated with each other.

The aetiology of multiple extra-articular cystic synovitis is obscure. Flu-like symptoms may bring it about, as reported by Matsuda et al. ${ }^{4}$ Rheumatoid nodules seeding the bursae were reported to result in chyliform bursitis, ${ }^{8} 12$ which is consistent with the findings in our case and that of Takahashi et al. ${ }^{5}$ However, rheumatoid nodules were not evident in some of the reported cases. ${ }^{2-4}$ Either rheumatoid nodules or extra-articular synovial cysts may just represent a sequela of the inflammatory process, which is yet to be determined.

1 Phillis BB. Nontraumatic disorders. In: Crenshaw AH, ed. Campbell's operative orthopaedics. 8th ed. St Louis: Mosby Year Book, 1992:1939-55.

2 Setoyama M, Fukumitsu M, Mizoguchi S, Kanzaki T. Multiple bursitis-A case with an unusual skin manifestation. Dermatology 1995;191:318-20.

3 Yasuda M, Ono M, Naono T, Nobunaga M. Multiple rheumatoid bursal cysts. J Rheumatol 1989;16:986-8.

4 Matsuda T, Komaki H, Kakei M, Uchimura S, Mihara K, Seita M. A case of multiple bursitis. [in Japanese]. Kyushu Seita $M$. A case of multip.
Ryumatis $1982 ; 1: 100-3$.

5 Takahashi H, Nagano M, Maehiro S. A case of chronic articular rheumatism with multiple pseudotumorous bursitis. [in Japanese]. Nihon Seikeigeka Gakkaisi 1971;45:138.

6 Palmer DG. Synovial cysts in rheumatoid disease. Ann Intern Med 1969;70:61-8.

7 Huston KA, Nelson AM, Hunde GG. Shoulder swelling in rheumatoid arthritis secondary to subacromial bursitis. Arthritis Rheum 1978;21:145-7.

8 Ginsberg MH, Genant HK, Yu TF, McCarty DJ. Rheumatoid nodulosis: An unusual variant of rheumatoid disease. Arthritis Rheum 1975;18:49-58.

9 Arnett FC, Edworthy SM, Bloch DA, McShane DJ, Fries JF, Cooper NS, et al. The American Rheumatism Association 1987 revised criteria for the classification of rheumatoid arthritis. Arthritis Rheum 1988;31:315-24.

10 Harris ED Jr. Clinical features of rheumatoid arthritis. In: Kelley WN, Harris ED Jr, Ruddy S, Sledge CB, eds. Textbook of rheumatology. 4th ed. Philadelphia: WB Saunders, 1993:874-911.

11 Kaye BR, Kaye RL, Bobrove A. Rheumatoid nodules: review of the spectrum of associated conditions and proposal of a new classification, with a report of four seronegative cases. Am J Med 1984;76:279-92.

12 Taccari E, Teodori S. Rheumatoid chyliform bursitis: pathogenetic role of rheumatoid nodules. Arthritis Rheum $1984 ; 27: 221-6$. 